RU Компаративные фразеологические единицы

с отрицательным оценочным характером

в кабардино-черкесском языке

\begin{abstract}
Дзуганова Р. Х., Битокова С. Х., Ошроева К. В.
Аннотация. В статье рассматриваются компаративные фразеологизмы, ориентированные на человека с отрицательными чертами характера, в кабардино-черкесском языке. Цель исследования выявить компаративные фразеологизмы, регулярно используемые в роли образов-эталонов с отрицательной репрезентацией; определить отрицательные качества, находящие отражение в них; показать их реализации в художественном тексте. Научная новизна заключается в том, что впервые на основе анализа фактического материала выявляются отрицательные качества человека, воплощенные большей частью в образах-эталонах диких и домашних животных. Полученные результаты показали, что через указанные образы передаются такие отрицательные качества человека, как «небрежность», «беспомощность», «корыстолюбие», «злость», «беспощадность» и др.
\end{abstract}

\title{
Comparative Phraseological Units with Negative Evaluation in the Kabardino-Circassian Language
}

\author{
Dzuganova R. Kh., Bitokova S. Kh., Oshroeva K. V.
}

\begin{abstract}
The article examines comparative phraseological units with negative person evaluation in the Kabardino-Circassian language. The research objectives are as follows: to identify comparative phraseological units describing typical human sins, to determine what negative qualities they represent, to show their realization in a literary text. Scientific originality of the study lies in the fact that relying on an analysis of factual material, the authors for the first time identify the personality's negative qualities represented through stereotypic images of wild and domestic animals. The findings indicate that the mentioned images are associated with such negative qualities of a human being as "negligence”, "helplessness", "greed”, "malice”, 'mercilessness", etc.
\end{abstract}

\section{Введение}

В современной лингвистической науке со становлением антропоцентрической парадигмы, ориентированной на человека, актуализировались исследования фразеологического фонда. Известно, что во фразеологизмах отражаются мышление общества, его специфическое мировосприятие, его творческая, культурная сущность. Недаром А. В. Кунин назвал фразеологию «сокровищницей языка» [8, с. 4].

Фразеологический уровень наиболее ярко проявляет специфику языковой картины мира, подтверждая тем самым факт взаимовлияния языка и культуры. Поиск решения вопроса связи культуры и языка привел к созданию лингвокультурологии, которая, по определению В. Н. Телия, является «научной дисциплиной, исследующей воплощенные в живой язык материальную культуру и менталитет, проявляющиеся в языковых процессах, в их действенной преемственности с языком и культурой этноса» [15, с. 216].

В адыгских (черкесских) языках имеются исследования по некоторым культурным концептам. Описания наиболее важных культурных концептов на материале адыгских языков принадлежат 3. Х. Бижевой [3, с. 3]. Так, она пишет, что к ключевым культурным концептам любой языковой картины мира относится концепт ЧЕЛОВЕК [3, с. 12].

В адыгской этнокультурной традиции представление о человеческой личности связано с благожелательностью - «этикетной, то есть благородной, достойной уважения личностью...» [4, с. 12]. 
Между тем в данной статье рассматриваются компаративные фразеологизмы, в центре которых находится концепт ЧЕЛОВЕК с отрицательной коннотацией. Материалом для исследования выступает художественный текст.

Актуальность избранной темы заключается в том, что изучение концепта ЧЕЛОВЕК с его разными проявлениями позволит обнаружить все функциональные и стилистические особенности, а выявления отрицательных сторон человека, человеческого характера, его внешности, поведения, состояния, отношения к людям и т.д. через компаративные фразеологизмы, устойчивые сравнения, бесспорно, вписываются в разработку актуальных задач современной лингвистики.

Задачи исследования:

1. Выбрать из художественных текстов фразеологизмы компаративного типа с отрицательной смысловой репрезентацией, ориентированные на человека.

2. Распределить эмпирический материал по тематическим группам:

а) натуромерные;

б) артефактные;

в) антропомерные.

3. Определить отрицательные признаки, лежащие в основе компаративных фразеологизмов.

В работе использовались методы систематизации, классификации и контекстуального анализа.

Теоретической базой данного исследования послужили положения, выдвинутые известными отечественными лингвистами по структуре и семантике сравнения, стилистической маркированности, этноспецифичности исследуемых компаративов, их соответствия однословным наименованиям и т.д. (А. В. Кунин [8], В. Н. Телия [15], 3. Х. Бижева [4], Б. Х. Бгажноков [2]).

Практическая значимость работы заключается в том, что результаты исследования могут способствовать значительному расширению теории национальных языков, они могут быть использованы при сопоставительных исследованиях по фразеологии в разноструктурных языках, а также в педагогической практике в вузе при подготовке специалистов в области лингвокультурологии (при чтении курсов по сопоставительной типологии).

Устойчивые сравнительные сочетания с отрицательной коннотацией, ориентированные на человека, выявленные нами из художественных текстов, подверглись классификации по тематическим группам. Выделены три группы: натуромерная, артефактная, антропомерная. Рассмотрим особенности каждой группы в отдельности.

\section{Натуромерная группа компаративных фразеологических единиц с отрицательной коннотацией}

В натуромерной группе выделяются зоонимы, которые допускают классификацию на более мелкие рубрики: а) домашние животные; б) дикие животные; в) птицы. Они выступают репрезентантами отрицательных признаков, качеств человека.

Сравнения с домашними животными

Наибольшее число компаративных фразеологизмов с отрицательной репрезентацией составляют эталоны сравнения ЧЕЛОВЕКА с собакой. Например: хьэхъу бзаджэжь нэхъей как злая старая собака. (Маржан) абы хъэхъу бзаджэжь зыпыІуидз нэхъей пикІуэтащ [12, н. 152]. / (Маржан) отскочила от него как от злой старой собаки (здесь и далее перевод авторов статьи. - Р. Д., С. Б., К. О.). Пренебрежительное, отрицательное отношение к человеку усиливается добавлением аффикса -жь со значением старый к имени бзаджэ - бзаджэ-жь «злой».

Сравнения компаративного типа с собакой могут быть разными. Ср.: хьэ щтам хуэдэу как перепуганная собака. С помощью данного компаратива передается тревожное состояние: И щхъэщыр бапхъэ хъужауэ (цІыхубзыр) бауэбапщэу, хьэ щтам хуэдэу зиплъыхьу ар къыщылъэтащ [Там же, н. 89]... / (Женщина) вскочила, как перепуганная собака, оглядываясь по сторонам...

Сравнение с перепуганным бараном мэл ягъэщтам ещхьу передает эмоциональное состояние человека в определенной ситуации. Например: Тембот, Лу, Саримэ, Рум, Дисэ сымэ, мэл ягъэщтам ещхьу, я щхьэр щІахьауэ Гъумархэ я унэм щынэсам, унэм щІэзу цІыхур щІэст [10, н. 162]... / Когда Тембот, Лю, Сарима, Рум и Диса, понурив голову, как перепуганные бараны, прибежали к дому Гумара, в комнате было полно народу...

Обращает на себя внимание использование антонимичных образов козленка и буйвола для передачи неприятных звуков, таких как блеяние козленка и мычание буйвола: чыцІ гъуэм ещхьу, хэт хьэрэ бу ещхьу, которые нарушают покой и вселяют тревогу. Например: Жасыр кбэсри мухьэрэб зыбжанэм зэпэджэжу кбиІукІащ, муазинхэм я макъ Жьгъырухэр: хэт псыгъуэрэ чыцІ гъуэм ещхьу, хэт гъумрэ хьэрэ бу къыпфІэщІу [7, н. 12]... / Пришло время вечернего намаза, и из минаретов послышались перекликающиеся разные голоса муэдзинов: у одних - тонкие, как блеяние козленка, у других - грубые, как мычание буйвола.

Сравнивая двух героев - положительного и отрицательного - в одном предложении, писатель создает запоминающиеся образы. Ср.: А лІы бжыыфІэшхуэ Іэдэбымрэ иджы я учетчик, чыщІ ажэм ещхьу зызыгъэхъу Рикбэрэ зэрегъапщэ (абы) [9, н. 43]... / (Она) сравнивает этих двух мужчин: один видный, воспитанный, а другой - Рика - хорохорится как козленок...

Сравнения с котом, который украдкой ворует сливки, шащхьэ дыгъу кІуэ джэдум хуэдэу - ощущение стыда, стыдливость; желание сделать что-то запретное тайком. Адэшыпхъум къыдэхуэу Іуэху щІэн кбэнаІамэ зэфІиудыну, пщІантІэм зыщихущыхьырт (Сэфар) - зыщихущыхыырти, шащхьэ дыгъу кІуэ джэдум хуэдэу, гъуэлъыжыгъуэ зэрыхъуу лэгъунэм зыщІигъэхуэжырт [11, н. 89]. / (Сафар) озирался по двору в поисках дел, 
чтобы закончить быстро, и как только наступала ночь, возвращался в спальню тайком, как кот, подбирающийся украдкой к сливкам.

Сравнения ЧЕЛОВЕКА с теленком шкІэ, буйволенком хывышкІэ в составе сравнительных оборотов передают значения небрежности. Ср., например: Псы бэкбур щынэхъ куууІуэм, щынэхъ зэвым деж щыІуащІэрти, хьэрэшкІэм хуэдэу цІыкІухэм абы зыхагъэукІуриежырт [Там же, н. 34]. / Дети запрудили речку в том месте, где она была уже и глубже, а теперь валяются там, как буйволята. Ср. также: Іэхъуэм мыкІуэу шкІащІэхэм яхэзэрыхь хабзэ танэжь хуэдэ, хьэблэ сабийм я мыныбжьми дэджэгуэгъу яхуэхбуауэ зы щІалэ мывмышкІэфI гуэр яхэтт, махуэр зи кІыхьагъым [Там же, н. 29]. / Подобно бычку, примкнувшему к новорожденным телятам, один юноша-переросток играл целый день с квартальными мальчишками.

Сравнение с откормленным быком вы гъэшхам хуэдэ передает непристойное поведение - нарушение правил адыгского этикета - жадный к еде, ненасытный (обжорство). Ср.: Гугъу зумыгъэхьу, пхуэшхынум хуэдиз пшхыуэ егъажьи еплъыжыт - уэлэхьи, вы гъэшхам хуэдэу узэгуэкІыкІынум [19, н. 56]. / Если ты будешь только сидеть, ничего не делать и есть, сколько влезет, ты потолстеешь, как откормленный бык.

Сравнения с дикими животными

Сравнение ЧЕЛОВЕКА с дикими животными, например с голодным волком дыгъужь нэщІам хуэдэу, демонстрирует неприличное, непристойное поведение, противоречащее стереотипам обыденного сознания, сложившимся в адыгском языковом коллективе. Хъуэжэ Іэнэр щигъэкІуатэм, хьэщІэм дыгъужь нэщІам хуэдэу шхэуэ щцІизащ [13, н. 33]. / Как только Ходже поставил стол перед гостем, тот начал есть, как голодный волк.

Сравнение ЧЕЛОВЕКА с волком, отправившимся за жертвой хьэжэбажащэу ежьа дыгъужьым хуэдэу передает такие негативные черты, как алчность, беспощадность. Бэрокъуэр ежьащ, хьэжэбажащэу ежьа дыгъужьыжьу зиплъыхьу [16, н. 58]... / Бороков тронулся в путь, оглядываясь по сторонам, как волк, отправившийся за своей жертвой (добычей)...

Сравнение ЧЕЛОВЕКА с шакалом хьэІуцыдзым хуэдэу передает жестокий, беспощадный характер человека. Однословное сравнение человека с этим хищным животным семейства собачьих говорит о безжалостном, аморальном поведении человека. Бахъсэн аузым хьэІуцыдзым хуэдэу, щыызэблэурт сонэ бандэри, кбэрэщей бандэри, ди хэку бандэри [6, н. 19]. / В дореволюционное время в Баксанском ущелье шастали, как шакалы, грузинские банды, карачаевские банды, а также и наши банды.

Для эталонизации недовольного, нервного ЧЕЛОВЕКА используется компаративное сочетание и мычэзууэ къыщахуа мыщэхъу Іэлым ещхьу как разбяренный медведь, которого разбудили не вовремя. Лвакбуэхэр дэгъэзеяуэ гум къихуа Елджырыкъуэ псори къыщыдыхьэшхыурэ къыщыпщыжри, и мычэзууэ къыщахуа мыщэхъу Іэлым ещхьу зэм адэкІэ... зэми мыдэкІэ щІэплбу... выгум лбэщІыхьэжри гупкІэм дэлбеижащ [12, н. 122]. / Эльджаруко неуклюже выпал из повозки так, что все хохотали над ним, а он, как разъяренный медведь, которого разбудили не вовремя, посмотрел по сторонам... догнал повозку и впрыгнул в нее обратно.

Репрезентантом очень некрасивой внешности человека в адыгской культуре считается внешность обезьяны, вызывающая отрицательные эмоции. Чачэ гъурт, фІыцІэт, цІыхухъуфэт... номин жыэпкъым ещхв и жьэпкъым хьэмцІыракІэ зырызи къытепIиикІырт [10, н. 69]. / Чача была худая, смуглая, мужеподобная... на подбородке, как у обезьяны, виднелись бородавки.

Сравнения с птицами

Сравнение ЧЕЛОВЕКА с замерзшим индюком гуэгушыхъу пІыщІам ещхьу олицетворяет бессилие, беспомощность, трусость. Ср. на примере: А тІум (Щэрданымрэ Аралпымрэ) япэмыжыжьэу гуэгушыхъу пІыщІам ещхьу зызэфІигъэпщхьауэ, щытт Гъуумари [Там же, н. 261]. / Недалеко от них (Шарданова и Аральпова), как замерзший индюк, стоял Гумар.

Давление сильного над слабым, чувства боязни и страха передаются через сравнение къашыргъэр зыхэуа джэд гупу подобно курам, на которых налетел ястреб: Темыр и щхьэр ирихьэхауэ и фІэщу здэщыпэм, гу лъетэ: пхафэм ит цІыху къомыр, къашыргъэр зыхэуа джэд гупу зэбгролъэт [5, н. 70]. / Темир, сосредоточенно собирая колосья, замечает: люди, находящиеся на стерне, бросились врассыпную, как куры, на которых налетел ястреб.

\section{Артефактная группа компаративных фразеологических единиц с отрицательной коннотацией}

Сравнение ЧЕЛОВЕКА с артефактами: со старым мешком къэпыжыым хуэдэу передает небрежное, презрительное отношение к кому-л. Губжыыр я нэм къыщІихыу пхъуэщ, зэпаубыдщ сэлэтхэми (фызыжьыр), къэпыжыым хуэдэу машинэ лъагэм драутІыпщхьеящ [18, н. 162]. / Солдаты схватили старушку и забросили в кузов машины, будто старый мешок.

В сравнении ЧЕЛОВЕКА с горящей свечкой щэху уэздыгъэу къегъэткІухын можно усматривать значение корыстолюбия - укрощение кого-л., сделать кого-л. покладистым. Унагъуэ дыхъумэ (егупсысащ хъыджэбзыр) сэ ар (щІалэр) шэху уэздыгъэу къезмыгъэткІухмэ [17, н. 258]! / Когда поженимся (подумала девушка), я его заставлю расплавиться, как горящая свечка!

Неполноценность, тупость объекта может передать сравнение ЧЕЛОВЕКА с юлой чыныжь хуэдэ. Псори вэржьэр зэрыгъэхъуащ: махуэ псом ефэн фІэкІа Іуэху зимыІа поручик Михееври апхуэдизкІэ хьэлэл хъуащи, чыныжь хуэдэу утыкум щоджэрэз [1, н. 103]. / Все загудели: и поручик Михеев, который весь день только и делал, что пил, настолько подобрел, что закрутился в кругу, как юла. 


\section{Антропомерная группа компаративных фразеологических единиц с отрицательной коннотацией}

Эталоны сравнения ЧЕЛОВЕКА с ЧЕЛОВЕКОМ, запечатленные в художественных произведениях с отрицательной репрезентацией, встречаются редко. Ср., например: Сэри сыундэрэбжьауэ, си хьэлбэр сІыцъыу, жьым зэщІиубыда, зи ныбжь нэса лІыжь хуэдэ, селъэбышауэу сежьэжащ [20, н. 12]. / И я тоже, оцепеневший со своим грузом, будто столетний старик, прихрамывая, пошел дальше. Таким образом, сравнение мальчика со стариком указывает не только на физическое состояние мальчика, но также подчеркивается тяжелое материальное положение крестьян в то время.

Материальное состояние человека - богатство - категоризируется через сочетание лІакъуэлІэшыжь нэхъей как дворянин. Сравнивая кузнеца, сидящего без работы, с дворянином, автор выставляет его как бездельника, подчеркивая негативное отношение рабочего класса к дворянскому сословию в послереволюционное время. (Къэжэр ХьэкІашэ жиІэу:) Жылэр губгъуэм итщ пщІантІэпсыр я жьэкъыпэм къыпыжу, уэ, лІакъуэлІэшыжь нэхъей, фошыгъу шей уофэри ущысщ [14, н. 31]! / Весь народ сейчас работает на поле в поте лица, а ты, как дворянин, пьешь чай с сахаром и сидишь тут!

\section{Заключение}

Выводы:

1. Компаративные фразеологические единицы дают возможность систематизировать окружающую действительность, давая образную характеристику предметам, а компаративные сочетания формируют эталоны, которые становятся своеобразными ценностными ориентирами для данного языкового сообщества.

2. Выборка из художественных текстов компаративных фразеологизмов с отрицательной репрезентацией, ориентированных на человека, позволяет заключить, что в кабардино-черкесском языке представлен богатый материал для дальнейшего исследования.

3. Анализ компаративных фразеологизмов показал, что натуромерные компаративные фразеологизмы в анализируемом языке образуют самую продуктивную группу. Артефактные и антропомерные компаративные фразеологические единицы с отрицательной коннотацией представлены небольшими группами.

4. Анализ материала позволил выявить ряд отрицательных признаков, лежащих в основе компаративных фразеологизмов, ориентированных на ЧЕЛОВЕКА. Это негативные особенности, связанные: а) с физическим состоянием; б) с их поступками; в) с характером; г) с отношениями к людям; д) с поведением, манерами; е) с эмоциональным состоянием; ж) с отсутствием умственных способностей.

Перспективы дальнейшего исследования мы видим в разработке полной лексико-семантической платформы по натуромерным эталонным сравнениям с отрицательным оценочным характером, ориентированным на человека, в кабардино-черкесском языке.

\section{Список источников}

1. АбытІэ В. Къ. ЩІакІуэр зи унэ. Черкесск: Ставрополь тхылъ тедзапІэ. Къэрэшей-Шэрджэс отделенэ, 1986. 256 н.

2. Бгажноков Б. Х. Очерки этнографии общения адыгов. Нальчик: Эльбрус, 1983. 232 с.

3. Бижева 3. Х. Адыгская языковая картина мира. Нальчик: Эльбрус, 2000. 124 с.

4. Бижева 3. Х. Культурные концепты в кабардинском языке. Нальчик: КБГУ, 1997. 140 с.

5. Дыгъужь Къу. Б. ЩІымахуэ лэгъупыкъу. Черкесск: РГУ «Къэрэшей-Шэрджэс тхылъ тедзапІэ», 2011.174 н.

6. Елгъэр К. М. Ухеймэ - улъэщщ. Налшык: Эльбрус, 1976. 348 н.

7. Елмэс І. М. Бгъэхэм къуршым къагъэзэж: роман. Налшык: Эльбрус, 1993. 448 н.

8. Кунин А. В. Курс фразеологии английского языка. М.: Высшая школа, 1986. 396 с.

9. Къэрмокъуэ М. Азэмэт. Налшык: Эльбрус, 1984. 392 н.

10. КІыщокъуэ А. П. Хъуэпсэгъуэ нур: тхыгъэхэр томихым щызэхуэхьэсауэ. Налшык: Эльбрус, 2005. Т. 2.488 н.

11. КІэрэф М. Ж. Лъэужь е лІэужь. Налшык: Эльбрус, 2009. 572 н.

12. МафІэдз С. Мыхъур: повестхэр, рассказхэр. Налшык: Эльбрус, 2003. 344 н.

13. Махуэ А. М., КъардэнгъущІ 3. П. Хъуэжэ и таурыхъищэ. Майкоп: Адыгея, 1994. 126 н.

14. Нало 3. М. Къру закъуэ. Налшык: Эльбрус, 1981. 400 н.

15. Телия В. Н. Русская фразеология. Семантический, прагматический и лингвокультурологический аспекты. М.: Языки русской культуры, 1996. 287 с.

16. Теунэ Хь. И. Шэджэмокъуэ лъэпкъыр: тхыгъэ нэхъыщхьэхэр томитІу. ЕтІуанэ Іыхьэ. Налшык: Эльбрус, 1980. $568 \mathrm{н.}$

17. Хъуажь Ф. М. Уэрамэ сыт ебгъэщІэнт? Налшык: Принт центр, 2019. 335 н.

18. Хьэх С. Г. Лъагъуэр гъуэгум хуокІуэ. Налшык: Эльбрус, 2013. 624 н.

19. Хьэх С. Г. Махуэм дунейр и кІыхьагъщ. Налшык: Эльбрус, 1992. 304 н.

20. ЩоджэнцІыкІу А. Хьэжыгъэ пут закъуэ: тхыгъэхэр томитІу. Налшык: Къэбэрдей-Балъкъэр тхылъ тедзапІэ, 1961. Т. 2. 480 H. 


\section{Информация об авторах | Author information}

RU Дзуганова Рита Хабаловна ${ }^{1}$, д. филол. н. Битокова Светлана Хаутиевна ${ }^{2}$, д. филол. н. Ошроева Карина Вячеславовна ${ }^{3}$

${ }^{1}$ Институт гуманитарных исследований филиал Кабардино-Балкарского научного центра Российской академии наук, г. Нальчик 2,3 Кабардино-Балкарский государственный университет имени Х. М. Бербекова, г. Нальчик

EN Dzuganova Rita Khabalovna ${ }^{1}$, Dr Bitokova Svetlana Khautievna ${ }^{2}$, Dr Oshroeva Karina Vyacheslavovna ${ }^{3}$ ${ }^{1}$ The Institute for the Humanities Research Branch of the Kabardian-Balkarian Scientific Center of the Russian Academy of Sciences, Nalchik ${ }^{2,3}$ Kabardino-Balkarian State University named after H. M. Berbekov, Nalchik

${ }^{1}$ dzug.rita@yandex.ru, ${ }^{2}$ rinkas@rambler.ru, ${ }^{3}$ karinzal@yandex.ru

\section{Информация о статье | About this article}

Дата поступления рукописи (received): 08.02.2021; опубликовано (published): 30.04.2021.

Ключевые слова (keywords): компаративные фразеологизмы; кабардино-черкесский язык; эталоны сравнения; comparative phraseological units; Kabardino-Circassian language; comparison standards. 